\title{
Hypoxia Reduces the Transcription of Fibrotic Markers in the Intestinal Mucosa
}

\author{
Simona Simmen ${ }^{\mathrm{a}}$ Max Maane $^{\mathrm{a}}$ Sarah Rogler ${ }^{\mathrm{a}}$ Katherina Baebler ${ }^{\mathrm{a}}$ \\ Silvia Lang ${ }^{\text {a }}$ Jesus Cosin-Roger ${ }^{a}$ Kirstin Atrott ${ }^{a}$ Isabelle Frey-Wagner ${ }^{a}$ \\ Partick Spielmann ${ }^{b, c}$ Roland H. Wenger ${ }^{b, c}$ Bruce Weder $^{a}$ Jonas Zeitz ${ }^{a, d}$ \\ Stephan R. Vavricka ${ }^{a} \quad G^{2}$ hard Rogler ${ }^{a, c} \quad$ Cheryl de Vallière $^{a}$ \\ Martin Hausmann ${ }^{a}$ Pedro A. Ruiz ${ }^{a}$

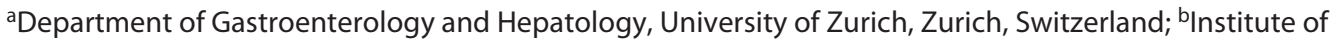 \\ Physiology, University of Zurich, Zurich, Switzerland; 'Zurich Center for Integrative Human Physiology (ZIHP), \\ University of Zurich, Zurich, Switzerland; ' ${ }^{\text {Center }}$ of Gastroenterology, Clinic Hirslanden, Zurich, Switzerland
}

\section{Keywords \\ Inflammatory bowel diseases · Wound healing · Epithelial- mesenchymal transition · Intestinal epithelial cells · Gut fibroblasts}

\begin{abstract}
Introduction: Intestinal fibrosis, characterized by excessive deposition of extracellular matrix proteins, is a common and severe clinical complication of inflammatory bowel disease (IBD). However, the mechanisms underlying fibrosis remain elusive, and currently, there are limited effective pharmacologic treatments that target the development of fibrosis. Hypoxia is one of the key microenvironmental factors influencing intestinal inflammation and has been linked to fibrosis. Objective: In the present study, we sought to elucidate the impact of hypoxia on fibrotic gene expression in the intestinal mucosa. Methods: Human volunteers, IBD patients, and dextran sulphate sodium-treated mice were exposed to hypoxia, and colonic biopsies were collected. The human intestinal epithelial cell line Caco-2, human THP-1 macrophages, and primary human gut fibroblasts were subjected to hypoxia, and changes in fibrotic gene expression were assessed. Results: Human volunteers subjected to hypoxia
\end{abstract}

karger@karger.com www.karger.com/iid

Karger!

BOPEN ACCESS
(C) 2021 The Author(s)

Published by S. Karger AG, Basel

This is an Open Access article licensed under the Creative Commons Attribution-NonCommercial-4.0 International License (CC BY-NC) (http://www.karger.com/Services/OpenAccessLicense), applicable to the online version of the article only. Usage and distribution for commercial purposes requires written permission. presented reduced transcriptional levels of fibrotic and epithelial-mesenchymal transition markers in the intestinal mucosa. IBD patients showed a trend towards a decrease in tissue inhibitor of metalloproteinase 1 protein expression. In mice, hypoxic conditions reduced the colonic expression of several collagens and matrix metalloproteinases. Hypoxic Caco- 2 cells, THP- 1 cells, and primary gut fibroblasts showed a significant downregulation in the expression of fibrotic and tissue remodelling factors. Conclusions: Stabilization of hypoxia-inducible factors might represent a novel therapeutic approach for the treatment of IBD-associated fibrosis.

(c) 2021 The Author(s)
Published by S. Karger AG, Basel

\section{Introduction}

Intestinal fibrosis is a frequent and severe complication in Crohn's disease (CD) and ulcerative colitis (UC), the main clinical manifestations of inflammatory bowel disease (IBD) [1]. IBD-associated fibrosis is linked with colonic wall thickening, fibrotic strictures, and stenosis and ultimately leads to irreversible tissue dysfunction and

Martin Hausmann and Pedro A. Ruiz contributed equally. 
obstruction of the bowel [2]. Disease complications such as strictures, fistulas, and abscesses are the main indication for surgery, leading to one-third of $\mathrm{CD}$ patients undergoing surgical resection of fibrotic intestinal tissue [3]. Consequently, a better understanding of the mechanisms of IBD-associated fibrosis, as well as further insights into possible therapeutic approaches, is essential to address this major health problem.

In response to tissue injury and inflammation, processes involved in promoting tissue repair (healing) are triggered in the intestinal mucosa. The wound healing response requires highly organized modulation of various factors and cell types, including immune cells, mesenchymal cells, and epithelial cells, in the wound region. This process involves 3 seamless and overlapping phases: the inflammatory phase, the proliferative phase, and the remodelling phase. During the inflammatory phase, resident cells produce factors that trigger the recruitment of immune cells into the injury. Infiltrating monocytes differentiate into macrophages and become the main cell population [4]. Mediators released during the inflammatory phase also recruit fibroblasts, thereby initiating the proliferative phase and a fibrogenic response characterized by the deposition of extracellular matrix (ECM) proteins, such as fibronectin and collagens, in the wound region. During the remodelling phase, matrix metalloproteinases (MMPs) are produced and degrade the preformed ECM scaffolds. If the inflammatory phase is inappropriately sustained, an overeactive wound healing response, characterized by excessive deposition of collagen and other ECM proteins, can lead to fibrosis and scar tissue formation.

Tissue hypoxia is increasingly recognized as an important factor influencing the development of IBD. In fact, high levels of hypoxia-inducible transcription factors have been detected in colonic samples from IBD patients [5] and mouse models of colitis [6]. In chronically inflamed and fibrotic tissues, elevated consumption of oxygen by infiltrating inflammatory cells and active resident cells depletes the local oxygen, rendering the intestinal mucosa transiently hypoxic [7]. Limited vascular perfusion also leads to reduced oxygen availability in cells $[4,7]$. Consequently, hypoxia-mediated responses are critically involved in essentially all processes of inflammation and wound healing [8]. Transcriptional responses to hypoxia are regulated by a family of transcription factors known as hypoxia-inducible factors (HIFs), which are tightly regulated by oxygen-dependent prolyl hydroxylases and factor-inhibiting HIFs [9]. Under normoxia, prolyl hydroxylation leads to proteasomal degradation of the HIFa sub- units, whereas asparaginyl hydroxylation inhibits $\mathrm{HIFa}$ transcriptional activity [10]. During hypoxia, HIF a subunits translocate to the nucleus, where they heterodimerize with the common $\beta$ subunit and bind to the regulatory regions of target genes, allowing the tissue to adapt to hypoxia and promote survival processes. In view of the critical role of oxygen in cell survival and homeostasis, cells have evolved many molecular mechanisms that enable them to adapt to hypoxia [7, 11]. Moreover, there is mounting evidence that hypoxia triggers protective mechanisms that contribute to the resolution of inflammation in several models of IBD $[11,12]$. In conditional knockout mice, loss of HIF-1 $\alpha$ expression in the epithelium leads to more severe colitis, while transgenic overexpression of active HIF-1 $\alpha$ is protective [6]. Accumulated evidence shows that modulating hypoxia-associated pathways is a potential therapeutic approach in intestinal fibrosis; however, clinical studies are needed to confirm the therapeutic benefit of hypoxia in patients [13].

Transforming growth factor (TGF) $\beta$ is regarded as the principal mediator of fibrosis in virtually all organs, including the gut. TGF $\beta$ triggers proliferation and differentiation of fibroblasts and is a potent inducer of major ECM proteins, such as fibronectin and collagens [14]. TGF $\beta$ signalling also promotes epithelial-mesenchymal transition (EMT) [15], a process that involves the repression of the epithelial phenotype and the induction of mesenchymal factors, including the myofibroblast marker a-smooth muscle actin ( encoded by the ACTA2 gene), and increases cell transmigration through the basement membrane. In turn, the activity of TGF $\beta$ is attenuated or enhanced by other cytokines. For instance, interleukin-1 and tumour necrosis factor- $\alpha$, which modulate TGF $\beta$ signalling at several levels, are well-characterized pro-fibrotic cytokines that have been shown to be reduced by hypoxia, likely through the inhibition of nuclear factor $\kappa \mathrm{B}$ activity $[12,16]$. A better understanding of how fibrosis and wound healing processes are modulated by hypoxia will provide insights into possible therapeutic approaches for the treatment of intestinal fibrosis.

In previous studies, we have assessed the effects of hypoxia on colonic pro-inflammatory gene expression and signalling in vivo and cultured human intestinal epithelial cells (IECs) and monocytes [12, 17]. In the present work, we sought to elucidate the impact of hypoxia on fibrotic gene expression in colon biopsies of human subjects and mice, as well as Caco- 2 cells, macrophages, and primary gut fibroblasts. Our results point to reduced fibrotic processes in the gut through the transcriptional regulation of fibrosis-associated gene expression.
Simmen et al. 
Table 1. Participant characteristics

\begin{tabular}{|c|c|c|c|}
\hline Item & $\mathrm{HV}$ & $\mathrm{CD}$ & UC \\
\hline Subjects, $n$ & 10 & 11 & 9 \\
\hline Gender, female, $n(\%)$ & $3(30.0)$ & $6(54.5)$ & $5(55.6)$ \\
\hline Weight ${ }^{* * *}$, mean \pm SD (range), $\mathrm{kg}$ & $69.3 \pm 11.0(48-82)$ & $75.2 \pm 10.4(54-93)$ & $75.9 \pm 29.0(55-146)$ \\
\hline $\mathrm{BMI}$, mean $\pm \mathrm{SD}$ (range), $\mathrm{kg} / \mathrm{m}^{2}$ & nd & $24.9 \pm 2.0(22-29)$ & $24.8 \pm 8.1(19-44)$ \\
\hline Smoking status & $2 / 10(20.0 \%)$ & $3 / 11(27.3 \%)$ & $2 / 9(22.2 \%)$ \\
\hline Harvey-Bradshaw Index for CD patients (median, IQR) & na & 0.0 & na \\
\hline Partial Mayo Score for UC patients (median, IQR) & na & na & 0.0 \\
\hline \multicolumn{4}{|l|}{ Medical history } \\
\hline Azathioprine/6-MP & na & $5 / 11(45.5 \%)$ & $7 / 9(58.3 \%)$ \\
\hline Methotrexate & na & $1 / 11(9.1 \%)$ & 0 \\
\hline
\end{tabular}

6-MP, mercaptopurine; CD, Crohn's disease; HV, healthy volunteers; IQR, interquartile range; UC, ulcerative colitis; SD, standard deviation; na, not applicable; nd, no data; NSAID, non-steroidal anti-inflammatory drug; TNF, tumour necrosis factor.

\section{Methods}

\section{Human Subjects}

Healthy subjects $(n=10)$, patients with CD $(n=11)$, and patients with UC $(n=9)$ in stable remission were subjected to hypoxic conditions corresponding to an altitude of 4,000 m.a.s.l. for $3 \mathrm{~h}$ using a hypobaric pressure chamber at the Swiss Aeromedical Center in Dubendorf, Switzerland [18]. Clinical activity in patients with CD and patients with UC was assessed using the Harvey Bradshaw Index and the Partial Mayo Score, respectively. The participant characteristics are shown in Table 1. For endoscopy, Olympus EVIS EXERA III (GIF-H190) and Olympus EVIS EXERA (CFQ160) (Olympus Schweiz, Wallisellen, Switzerland) were used. Biopsies from the sigmoid colon were collected using standard size forceps $(2.4 \mathrm{~mm})$ the day before hypoxia, immediately after hypoxia, and 1 week after collection of the first sample at the Department of Gastroenterology and Hepatology of the University Hospital, Zurich. This study was approved by the Ethics Committee of the Canton of Zurich (KEK-ZH Nr. 2013-0284; date of approval: April 23, 2014), and all participants signed an informed consent form. The study protocol conformed to the ethical guidelines of the 1975 Declaration of Helsinki.

\section{Immunohistochemistry}

Intestinal specimens from the distal third of the colon were embedded in paraffin and cut in 5- $\mu \mathrm{m}$ sections with a microtome. Immunostaining for TIMP1 was performed on Leica Bond Max instruments using Refine HRP-Kits (Leica Biosystems, Newcastle, UK) and processed according to the manufacturer's instructions prior to the incubation with rabbit monoclonal TIMP1 antibody (cat. no. ab211926; Abcam, Cambridge, UK) at a 1:1,000 dilution. Rabbit anti-guinea pig (cat. no. P0141; Dako, Glostrup, Denmark) was used as a secondary antibody at a 1:100 dilution. Quantifica- tion was performed using Image Analysis Software (National Institutes of Health, Bethesda, MD, USA) [19] using the Colour Threshold tool, and the resulting value was normalized to quantification of nuclei staining.

\section{Mouse Experiments}

Female (C57BL/6J) mice between 8 and 10 weeks of age were administered with 2\% DSS [20] (MP Biomedicals) in drinking water ad libitum for 7 days and then subjected to hypoxia $\left(8 \% \mathrm{O}_{2}\right)$ in a normobaric hypoxic tent (Coy Laboratory Products, Grass Lake, MI, USA) for $18 \mathrm{~h}$. Mice were then euthanized, and colonic samples were collected. Mice kept under normoxic conditions $(21 \%$ $\mathrm{O}_{2}$ ) were used as control. Mice were exposed to $2 \%$ DSS in drinking water ad libitum for 5 days and were co-administered with $8 \mathrm{mg}$ DMOG (Frontier Scientific, Logan, UT, USA) dissolved in PBS injected intraperitoneally every second day, as previously described [21]. Control mice received PBS. After a recovery period, mice were killed at day 9 and distal colon biopsies were taken. All animal experiments were approved by the Veterinary Office of the Canton of Zurich, Switzerland (ZH216-2014; date of approval: December 5, 2016).

\section{Cell Culture and Exposure to Hypoxia}

Primary human fibroblasts were obtained from surgical resection specimens collected from healthy areas of the mucosa of a patient with colorectal carcinoma. The study was approved by the ethics committee of the University of Zurich (EK-1316; date of approval: January 19,2007) and was performed according to the Declaration of Helsinki. Human intestinal fibroblasts were isolated and cultured as described previously [22]. The isolated cells were cultured in DMEM supplemented with $10 \%$ fetal calf serum (VWR). Caco-2 cells were obtained from the German Collection of Cells and Microorganisms (DSMZ, Braunschweig, Germany) 
Table 2. TaqMan gene expression assays

\begin{tabular}{|c|c|c|}
\hline Gene & Full name & TaqMan assay ID \\
\hline \multicolumn{3}{|c|}{ Human genes } \\
\hline TGF $\beta$ & Transforming growth factor beta & Hs00998133_m1 \\
\hline ACTA2 & Actin alpha 2, smooth muscle & Hs00426835_g1 \\
\hline VIM & Vimentin & Hs00185584_m1 \\
\hline $\mathrm{CDH} 1$ & Cadherin 1 & Hs01023895_m1 \\
\hline $\mathrm{CDH} 2$ & Cadherin 2 & Hs00983056_m1 \\
\hline COL1A1 & Collagen type I alpha 1 chain & Hs00164004_m1 \\
\hline COL3A1 & Collagen type III alpha 1 chain & Hs00943809_m1 \\
\hline COL4A1 & Collagen type IV alpha 1 chain & Hs00266237_m1 \\
\hline MMP2 & Matrix metallopeptidase 2 & Hs01548727_m1 \\
\hline MMP3 & Matrix metallopeptidase 3 & Hs00968305_m1 \\
\hline MMP9 & Matrix metallopeptidase 9 & Hs00957562_m1 \\
\hline TIMP1 & Tissue inhibitor of metalloproteinase 1 & Hs01092512_g1 \\
\hline \multicolumn{3}{|c|}{ Mouse genes } \\
\hline TGF $\beta$ & Transforming growth factor beta & Mm00524541_m1 \\
\hline ACTA2 & Actin alpha 2, smooth muscle & Mm00725412_s1 \\
\hline VIM & Vimentin & Mm01333430_m1 \\
\hline $\mathrm{CDH} 1$ & Cadherin 1 & Mm01247357_m1 \\
\hline $\mathrm{CDH} 2$ & Cadherin 2 & Mm01162497_m1 \\
\hline COL1A1 & Collagen type I alpha 1 chain & Mm00801666_g1 \\
\hline COL3A1 & Collagen type III alpha 1 chain & Mm00802300_m1 \\
\hline COL4A1 & Collagen type IV alpha 1 chain & Mm01210125_m1 \\
\hline MMP2 & Matrix metallopeptidase 2 & Mm00439498_m1 \\
\hline MMP3 & Matrix metallopeptidase 3 & Mm00440295_m1 \\
\hline MMP9 & Matrix metallopeptidase 9 & Mm00442991_m1 \\
\hline MMP13 & Matrix metallopeptidase 13 & Mm00439491_m1 \\
\hline TIMP1 & Tissue inhibitor of metalloproteinase 1 & Mm01341361_m1 \\
\hline
\end{tabular}

and cultured in DMEM supplemented with $10 \%$ fetal calf serum (VWR, Dietikon, Switzerland). THP-1 cells were maintained in an RPMI medium (Invitrogen, Carlsbad, CA, USA) supplemented with $10 \%$ fetal calf serum (VWR). To induce differentiation, $40 \mathrm{nM}$ phorbol 12-myristate-13-acetate (Sigma-Aldrich, St Louis, MO, USA) was added to $0.5 \times 106$ cells $/ \mathrm{mL}$. In some experiments, THP1 cells were treated with $10 \mu \mathrm{g} / \mathrm{mL}$ LPS (Invitrogen, Carlsbad, CA, USA). Serum-starved cells were subjected to hypoxia $\left(0.2 \% \mathrm{O}_{2}\right)$ in a hypoxia chamber (Invivo 400, Baker Ruskinn, Bridgend, United Kingdom). Cells maintained in normoxia $\left(21 \% \mathrm{O}_{2}\right)$ for the same time period were used as controls.

\section{RNA Extraction and Real-Time Quantitative PCR}

Colonic tissue for RNA analysis was snap frozen in liquid nitrogen upon collection. For RNA extraction, Buffer RLT (Qiagen, Hombrechtikon, Switzerland) was added to the samples, and tissue was then disrupted using the GentleMACS Dissociator (Miltenyi Biotec, Gladbach, Germany). Total RNA from human and mice biopsies and cells was isolated using the RNeasy Plus Kit (Qiagen) following the manufacturer's instructions. The High-Capacity cDNA Reverse Transcription Kit (Applied Biosystems, Foster City, CA, USA) was used for reverse transcription according to the manufacturer's instructions. qPCR was performed using TAQMAN Gene Expression Assays (Applied Biosystems) (Table 2), using the following PCR programme: $20 \mathrm{~s}$ at $95^{\circ} \mathrm{C}$, followed by 40 cycles of $95^{\circ} \mathrm{C}$ for $3 \mathrm{~s}$ and $60^{\circ} \mathrm{C}$ for $30 \mathrm{~s}$ with the TaqMan Fast Universal Mastermix. Relative mRNA expression was determined by the comparative $\Delta \Delta \mathrm{Ct}$ method using beta-actin (ACTB) as the reference gene.

\section{Western Blot}

Total protein was harvested in M-PER lysis buffer (Thermo Fisher Scientific) supplemented with protease inhibitors (Roche Diagnostics, Mannheim, Germany). For each group, a total of 20 $\mathrm{mg}$ protein was transferred to a nitrocellulose membrane after electrophoretic separation. Antibodies against human HIF-1a (cat. no. NB100-479; Novus Biologicals, Littletown, CO, UK), human caspase 3 (cat. no. 9661; Cell Signaling Technology, ZA Leiden, The Netherlands), and beta-actin (cat. no. A5441; SigmaAldrich) were used at 1:1,000 dilution. After washing in Tris-buffered saline, the secondary antibody conjugated to horseradish peroxidase was added, and the membrane was incubated at room temperature for $1 \mathrm{~h}$. After washing in Tris-buffered saline, the proteins were visualized using the ECL Plus detection kit (Amersham, Velizy-Villacoublay, France).

\section{Statistics}

Statistical analysis was performed using 1-way ANOVA followed by Tukey's post-test or Student's $t$ test. Data are expressed as mean $\pm \mathrm{SEM}$, and results were considered significant if $p<0.05$.
90

Inflamm Intest Dis 2021;6:87-100 DOI: $10.1159 / 00051306$
Simmen et al. 


\section{Results}

Hypoxia Reduces the Levels of Pro-Fibrotic Markers in the Colon of Human Subjects

To study the effects of hypoxia on levels of fibrotic markers, healthy volunteers (HV) and IBD patients were exposed to hypoxia for $3 \mathrm{~h}$. The participant characteristics are shown in Table 1 . In healthy subjects, transcript quantification of distal colon biopsies revealed no changes in the mRNA levels of TGF $\beta$ after $3 \mathrm{~h}$ of hypoxia (Fig. 1a). Nonetheless, there was a clear trend towards a decrease of basal ACTA2 (Fig. 1b) and a significant reduction of vimentin mRNA levels 1 week after hypoxia (Fig. 1c). Interestingly, the mRNA levels of the epithelial marker cadherin $(\mathrm{CDH}) 1$ (E-cadherin) remained unchanged (Fig. 1d), while the mesenchymal marker $\mathrm{CDH} 2$ (N-cadherin) was significantly reduced following hypoxia (Fig. 1e). Accordingly, the mRNA levels of the ECM proteins collagen type I alpha 1 chain (COL1A1) (Fig. 1f) and collagen type IV alpha 1 chain (COL4A1) (Fig. 1g) showed a trend towards a reduction. Transcript levels of MMP2 (Fig. 1h), MMP9 (Fig. 1i), and TIMP1 (Fig. 1j) were also reduced following hypoxia. Immunostaining for TIMP1 of distal colon sections showed a trend towards reduced protein levels of TIMP1 1 week after hypoxia in HV and IBD patients (Fig. 1k). Taken together, our results indicate a hypoxia-mediated decrease in fibrotic markers in the human colonic mucosa.

Low Oxygen Reduces Fibrotic Gene Expression in Mice

To further study the influence of hypoxia in fibrosis, mice were subjected to normoxia or hypoxia for $18 \mathrm{~h}$. In previous studies, we have shown a strong accumulation of HIF-1 in the intestinal mucosa of mice after $18 \mathrm{~h} \mathrm{[12].}$ Hypoxia significantly reduced the mRNA levels of TGF $\beta$ (Fig. 2a), but not ACTA2 (Fig. 2b), vimentin (Fig. 2c), CDH1 (Fig. 2d), or CDH2 (Fig. 2e) in the colon. Notably, the transcription levels of fibril COL1A1 (Fig. 2f) and collagen type III alpha 1 chain COL3A1 (Fig. $2 \mathrm{~g}$ ) and network-forming COL4A1 (Fig. 1g) were significantly reduced under hypoxia, suggesting a reduction of ECM protein deposition under low oxygen conditions. While the mRNA levels of MMP2 only showed a tendency towards a decrease (Fig. 2i), constitutive levels of MMP9 (Fig. 2j), MMP3 (Fig. 2k), and TIMP1 (Fig. 2l) were significantly reduced under hypoxia, pointing to a blockage of tissue remodelling processes in mice under hypoxic conditions.

Hypoxia Reduces Fibrotic Gene

Expression in the Gut
Hypoxia Reduces Tissue Remodelling Markers in the Dextran Sulphate Sodium Mouse Model of Colitis

To elucidate the impact of hypoxia on dextran sulphate sodium (DSS)-mediated expression of tissue remodelling markers, mice were administered with 2\% DSS for 7 days in drinking water and subjected to normoxia or hypoxia for $18 \mathrm{~h}$. DSS-treated mice did not show an increase in the expression levels of TGF $\beta$ (Fig. 3a), COL1A1 (Fig. 3b), or MMP9 (Fig. 3c). In contrast, these mice presented an increased expression of tissue remodelling factors, including MMP3 (Fig. 3d), MMP13 (Fig. 3e), and TIMP1 (Fig. 3f) that was only significant for MMP3. Hypoxia significantly reduced DSS-induced MMP3 (Fig. 3d) transcript levels and showed a trend towards a decrease in MMP9 (Fig. 3c), MMP13 (Fig. 3e), and TIMP1 (Fig. 3f) mRNA, supporting a role for hypoxia in the reduction of tissue remodelling markers under inflammation. To shed light on the mechanisms underlying hypoxia-mediated reduction of these factors, mice were administered with $2 \%$ DSS for 5 days and co-administered with $8 \mathrm{mg}$ dimethyloxalylglycine (DMOG) - a hydroxylase inhibitor and HIF inducer - injected intraperitoneally every second day. DMOG significantly reduced the expression of MMP13 (Fig. 3k) and TIMP1 (Fig. 3l) and showed a trend towards a reduction of MMP9 (Fig. 3i) and MMP3 (Fig. 3j) levels, indicating that the regulatory effects of hypoxia on these genes are mediated by HIF. Given the lack of induction of TGF $\beta$ and COL1A1 in DSS-treated mice, the possible inhibitory effects of DMOG were not observable.

\section{Hypoxia Reduces the Expression of Pro-Fibrotic}

Factors in Primary Human Gut Fibroblasts

Fibroblasts and myofibroblasts are the main effector cells of fibrosis. Consequently, we aimed to study the impact of hypoxia on primary gut fibroblasts. We have previously shown that hypoxia triggers the accumulation of HIF-1 in vitro [12]. As expected, hypoxia triggered the accumulation of HIF-1 in fibroblasts (Fig. 4a). Cellular stress, such as oxidative stress, leads to the activation of the intrinsic apoptosis pathway [23]. To assess the impact of hypoxia in cell viability, activation of caspase 3 , the main executioner of apoptosis triggered by both the intrinsic and the extrinsic pathways [24], was studied. Our data do not show any differences in the cleavage of caspase 3 between normoxic and hypoxic fibroblasts (Fig. 4a), indicating that apoptosis was not triggered following $24 \mathrm{~h}$ hypoxia in these cells. Although TGF $\beta$ was not affected by hypoxia (Fig. 4b), the mRNA levels of the fibrotic markers ACTA2 (Fig. 4c) and vimentin (Fig. 4d) were significantly reduced, suggesting that hypoxia plays a preventive role

Inflamm Intest Dis 2021;6:87-100

DOI: $10.1159 / 000513061$ 

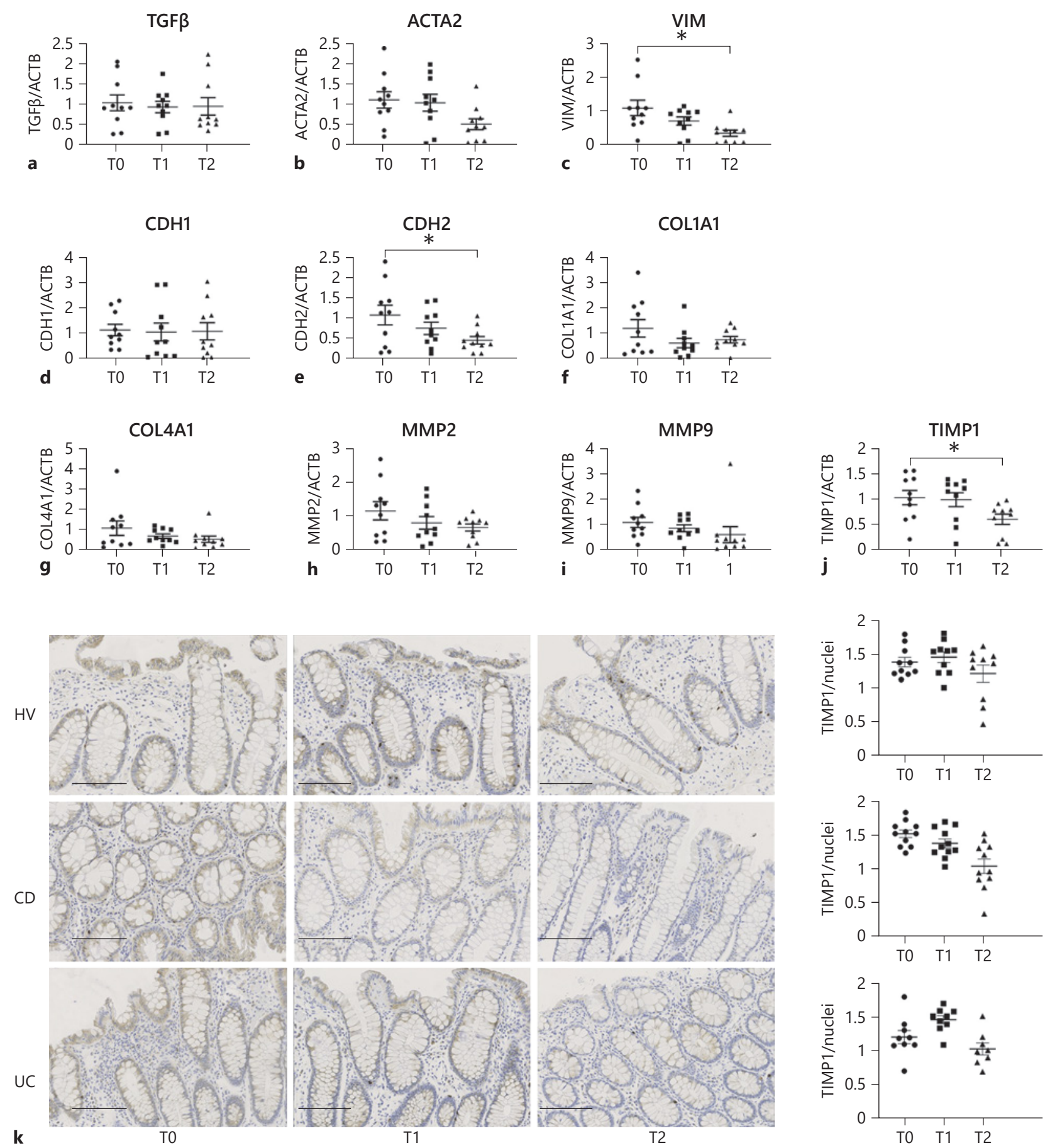

Fig. 1. Hypoxia reduces the levels of fibrotic markers in the colon of human subjects. $\mathrm{HV}(n=10)$, patients with $\mathrm{CD}(n=11)$, and patients with UC $(n=9)$ in stable remission were subjected to hypoxia in a hypobaric chamber simulating an altitude of 4,000 m.a.s.l. for $3 \mathrm{~h}$. Distal colon biopsies were taken the day before entering the hypobaric chamber (T0), immediately after hypoxia (T1), and 1 week after collection of the first biopsy (T2). Transcript quantification for TGF $\beta$ (a), ACTA2 (b), vimentin (c), CDH1 (d), CDH2 (e), COL1A1 (f), COL4A1 (g),
MMP2 (h), MMP9 (i), and TIMP1 (j) was performed in mRNA extracted from colon biopsies from HV. Immunostaining for TIMP1 (k) in intestinal specimens from $\mathrm{HV}$ and IBD patients was performed, and the areas of positive staining were quantified and normalized to nuclei staining. Scale bars, $25 \mathrm{~mm}$. Statistical analysis was performed using 1-way ANOVA followed by Tukey's post-test. Results represent mean + SEM; *, $p<0.05$. HV, healthy volunteers; CD, Crohn's disease; UC, ulcerative colitis; IBD, inflammatory bowel disease. 


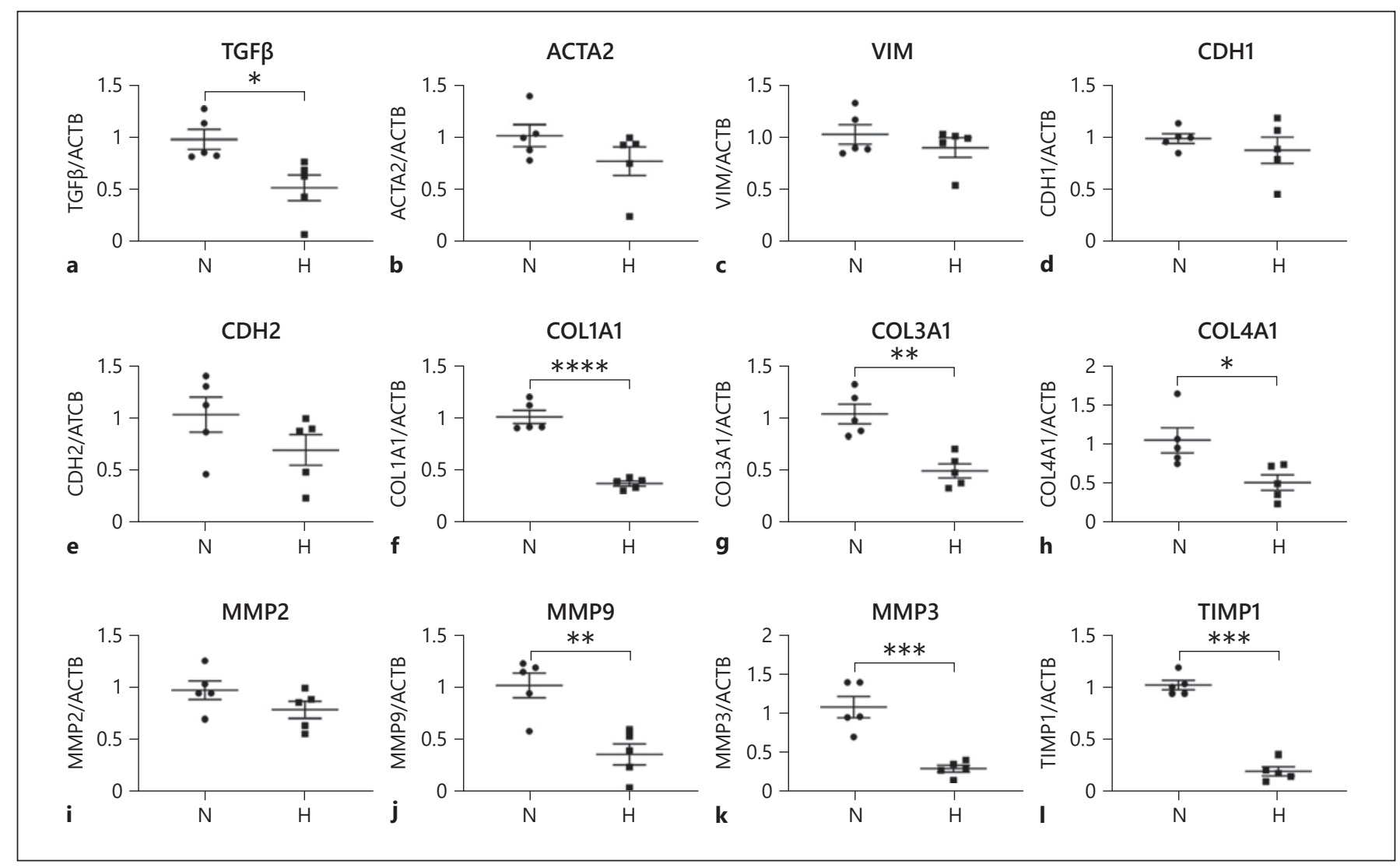

Fig. 2. Hypoxia reduces the expression of fibrotic markers in the colon of mice. Mice $(n=5)$ were subjected to normoxia $(\mathrm{N}, 21 \%$ $\mathrm{O}_{2}$ ) or hypoxia $\left(\mathrm{H}, 8 \% \mathrm{O}_{2}\right)$. After $18 \mathrm{~h}$, mice were sacrificed and colon biopsies were collected. Transcript quantification for TGF $\beta$ (a), ACTA2 (b), vimentin (c), CDH1 (d), CDH2 (e), COL1A1 (f),
COL3A1 (g), COL4A1 (h), MMP2 (i), MMP9 (j), MMP3 (k), and TIMP1 (I) was performed. Statistical analysis was performed using Student's $t$ test. Results represent mean + SEM; * $p<0.05 ;{ }^{* *}, p<$ $0.01{ }^{* * *}, p<0.001{ }^{* * * *}, p<0.0001$. in the differentiation of fibroblasts into myofibroblasts. Accordingly, hypoxia also significantly reduced the basal mRNA levels of COL1A1 (Fig. 4e), COL3A1 (Fig. 4f), and COL4A1 (Fig. 4g). Although MMP2 expression remained unaffected by hypoxia (Fig. 4h), the mRNA levels of MMP9 (Fig. 4i), and TIMP1 (Fig. 4j) were significantly downregulated. These data suggest that low oxygen levels repress fibrosis-associated gene expression in fibroblasts.

\section{Hypoxia Reduces the Expression of Fibrotic and EMT} Markers in Human IECs

Epithelial-derived fibrotic mediators and EMT play a key role in mucosal wound healing and fibrotic processes. Therefore we investigated the effects of low oxygen tension in the human IEC line Caco-2. As observed in fibroblasts, hypoxia failed to reduce basal TGF $\beta$ mRNA levels (Fig. 5a), but significantly reduced ACTA2 (Fig. 5b) and vimentin (Fig. 5c). In accordance with the results in hu- man subjects, $\mathrm{CDH} 1$ expression remained unchanged (Fig. 5d), while the EMT marker $\mathrm{CDH} 2$ was significantly reduced under hypoxia (Fig. 5e), pointing to a repression of basal EMT in hypoxic IECs. Interestingly, hypoxia reduced the transcript levels of network-forming COL4A1 (Fig. 5h), but not of fibril collagens COL1A1 (Fig. 5f) or COL3A1 (Fig. 5g). Hypoxic IECs also presented significantly reduced levels of TIMP1 (Fig. 5l), MMP9 (Fig. 5j), and MMP3 (Fig. 5k), but not MMP2 (Fig. 5i). Taken together, our results suggest that hypoxia preserves the epithelial phenotype of IECs and blocks constitutive expression of factors involved in tissue remodelling.

\section{Hypoxia Reduces Fibrotic Gene Expression in Human Macrophages}

Next, we sought to analyse the impact of hypoxia on the expression of fibrotic markers in cultured monocytes and phorbol 12-myristate-13-acetate-differentiated macro- 

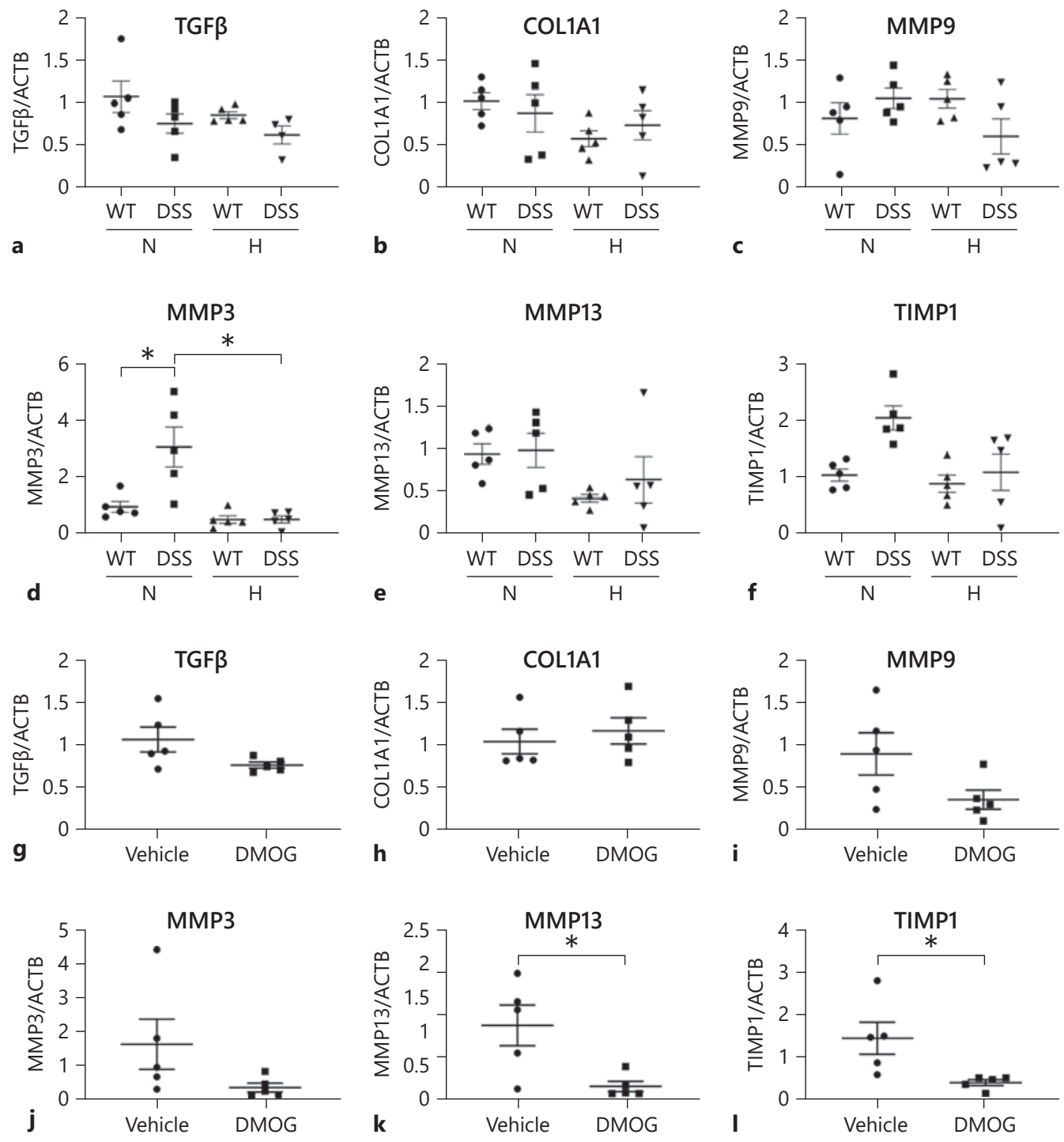

Fig. 3. Hypoxia and DMOG reduce the expression of tissue remodelling factors in the colon of DSS-treated mice. Mice were administered with DSS $(n=5)$ or DSS-free water $(n=5)$ and subjected to normoxia $\left(\mathrm{N}, 21 \% \mathrm{O}_{2}\right)$ or hypoxia $\left(\mathrm{H}, 8 \% \mathrm{O}_{2}\right)$. After $18 \mathrm{~h}$, mice were killed and colon biopsies were collected. Transcript quantification for TGF $\beta$ (a), COL1A1 (b), MMP9 (c), MMP3 (d), MMP13 (e), and TIMP1 (f) was performed. Statistical analysis was performed using 1-way ANOVA followed by Tukey's post-test. Results represent mean + SEM; ${ }^{*}, p<0.05$. Mice were administered

phages. Notably, hypoxia significantly reduced the mRNA levels of TGF $\beta$ in monocytes (Fig. 6a), but not in macrophages (Fig. 6g). ACTA2 mRNA was significantly reduced in both hypoxic monocytes (Fig. 6b) and macrophages (Fig. 6h), while vimentin remained unchanged (Fig. 6c, i). with 2\% DSS for 5 days and co-administered with 8 mg DMOG $(n=5)$ or vehicle $(n=5)$ injected intraperitoneally every second day. After a recovery period, mice were killed at day 9 , distal colon biopsies were collected, and transcript quantification for TGF $\beta$ (g), COL1A1 (h), MMP9 (i), MMP3 (j), MMP13 (k), and TIMP1 (I) was performed. Statistical analysis was performed using Student's $t$ test. Results represent mean $+\mathrm{SEM}{ }^{*}, p<0.05$. DMOG, dimethyloxalylglycine; DSS, dextran sulphate sodium.

Of note, hypoxia significantly increased COL1A1 mRNA in monocytes (Fig. 6d), while hypoxic macrophages showed a significant reduction in COL1A1 mRNA levels (Fig. 6j). MMP9 expression remained unchanged in hypoxia-treated monocytes (Fig. 6e) and macrophages (Fig. 6f). Finally, 


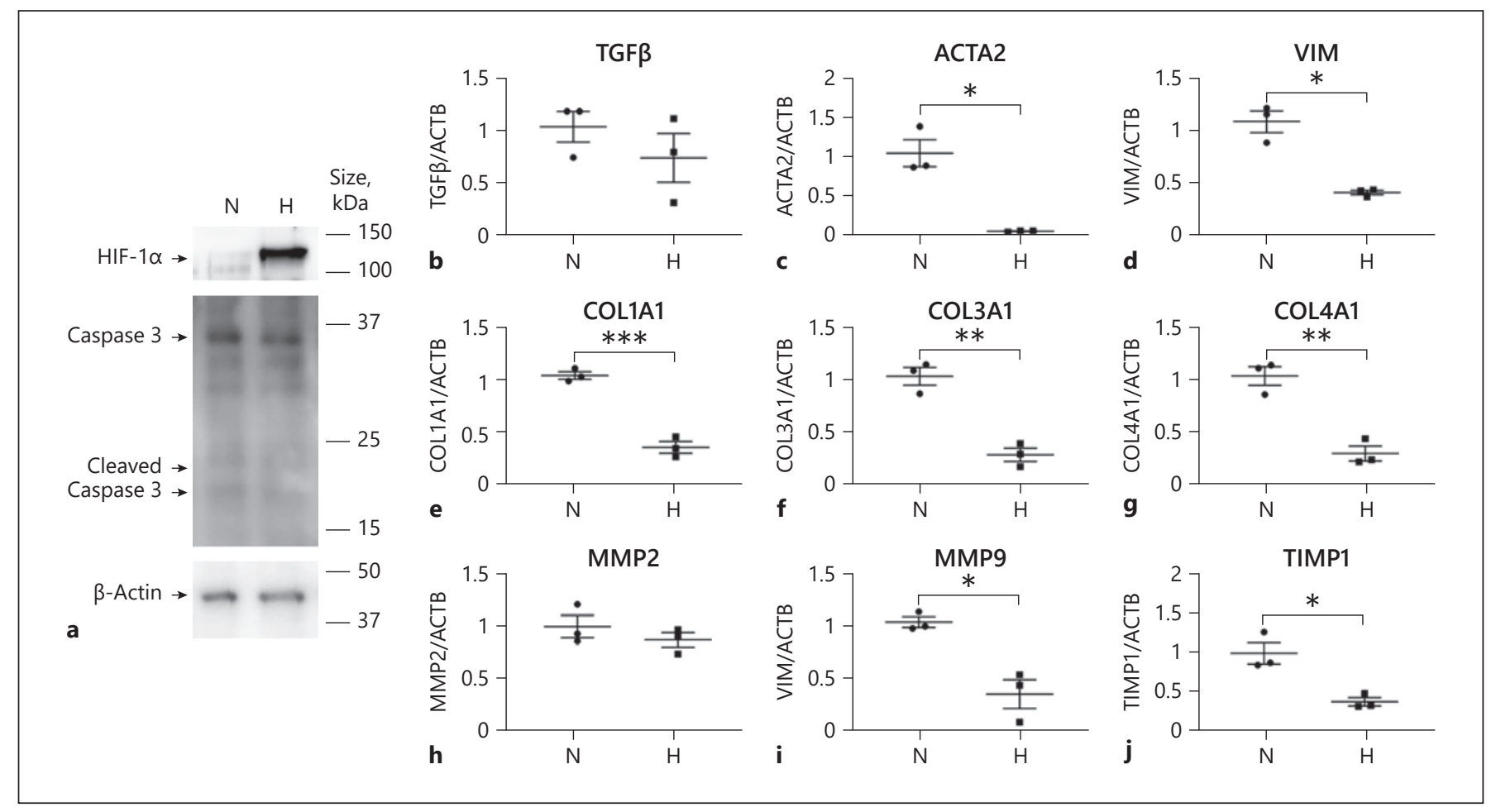

Fig. 4. Hypoxia reduces fibrotic gene expression in primary human gut fibroblasts. Primary human gut fibroblasts were subjected to normoxia $\left(\mathrm{N}, 21 \% \mathrm{O}_{2}\right)$ or hypoxia $\left(\mathrm{H}, 0.2 \% \mathrm{O}_{2}\right)$ for $24 \mathrm{~h}$. Total protein was isolated and Western blotting for HIF-1a and caspase 3 was performed. Transcript quantification for TGF $\beta$ (b), ACTA2

TIMP1 was significantly reduced in monocytes (Fig. 6f), but not macrophages (Fig. 61). In monocytes, LPS failed to induce TGF $\beta$ (Fig. $6 \mathrm{~m}$ ) or ACTA2 (Fig. 6n) mRNA expression, and hypoxia did not reduce the transcript levels of these fibrotic factors in the presence of LPS (Fig. $6 \mathrm{~m}, \mathrm{n}$ ). Interestingly, hypoxia significantly reduced LPS-induced expression of VIM (Fig. 6o), but not TIMP1 (Fig. 6p), where only a trend towards a decrease could be observed. These results suggest that hypoxia can downregulate the expression of fibrotic markers induced by inflammatory mediators in monocytes.

\section{Discussion}

Our study shows that hypoxia reduces the expression of mucosal markers of fibrosis-associated processes in vivo and in key cell types involved in intestinal inflammation and fibrosis. We have previously shown that hypoxia plays a protective role in colitis through the reduction of pro-inflammatory signalling and gene expression [12]. (c), vimentin (d), COL1A1 (e), COL3A1 (f), and COL4A1 (g), MMP2 (h), MMP9 (i), and TIMP1 (j) was performed. Statistical analysis was performed using Student's $t$ test. Results are representative of mean + SEM of 2 independent experiments performed with 3 replicates; * $p<0.05$; $^{* *}, p<0.01$; $^{* * *}, p<0.001$.

Overall, our data suggest that the anti-inflammatory effects of hypoxia span the regulation of IBD-associated fibrotic responses.

Transcript analysis of human colonic samples showed that hypoxia-associated pathways blocked the mRNA levels of fibroblast-like markers, including ACTA2, vimentin, and $\mathrm{CDH} 2$. Consistently, the mRNA levels of these factors were also significantly reduced in hypoxic Caco-2 cells. Moreover, the expression of the epithelial marker $\mathrm{CDH} 1$ remained unchanged in these cells, suggesting a blockage of EMT-associated processes in the intestinal epithelium. Additionally, hypoxia significantly downregulated vimentin and ACTA2 in human gut fibroblasts, demonstrating that tissue hypoxia plays a preventive role in the transdifferentiation of fibroblasts into myofibroblasts. These results are in contrast to several studies showing that hypoxic tumour microenvironment increases the metastatic potential of cancer cells via EMT [25]. Nonetheless, it should be noted that most studies on the role of hypoxia and HIF in EMT have been performed in the context of tumour hypoxia, and additional tumour 


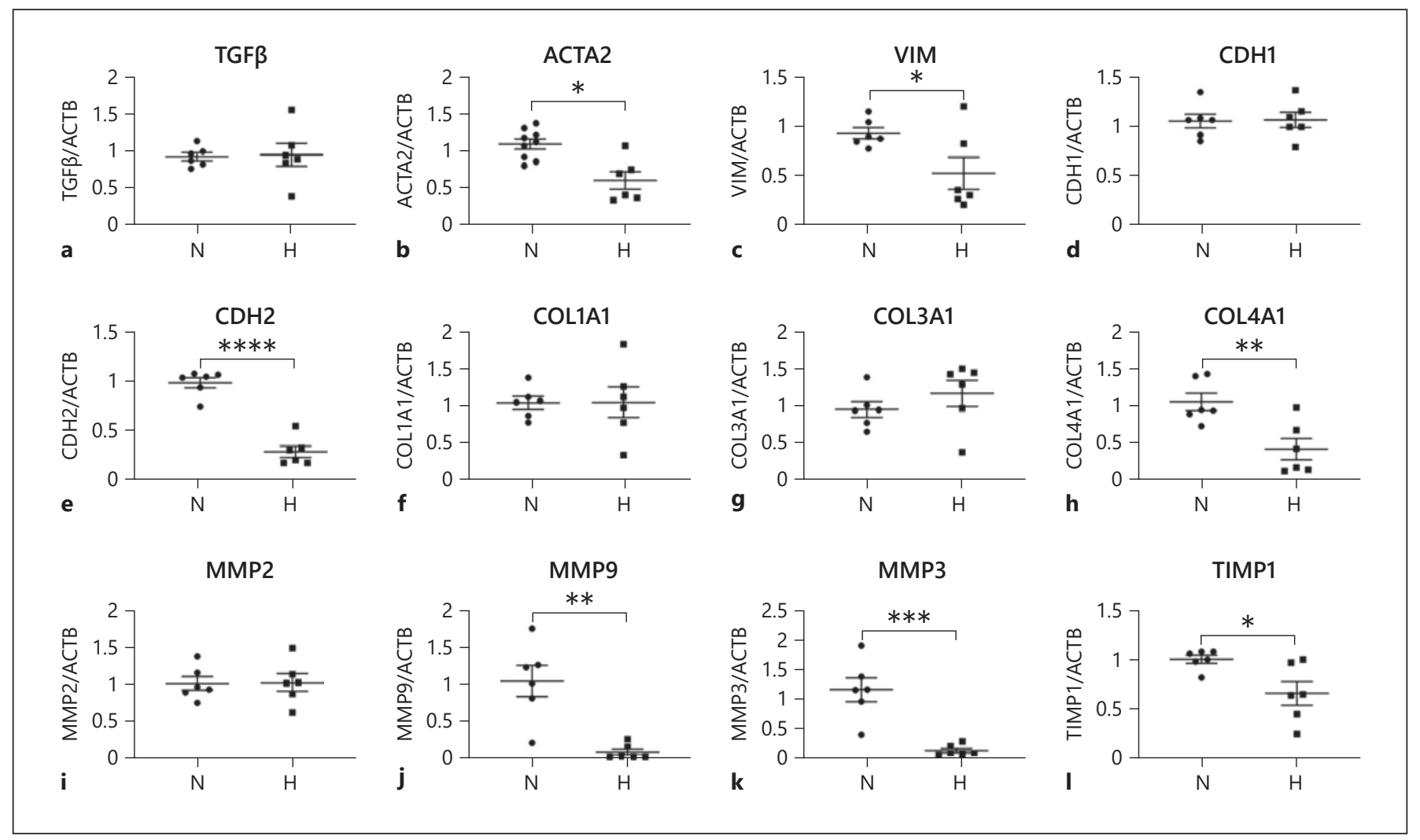

Fig. 5. Hypoxia reduces the expression of fibrotic factors in Caco2 cells. Caco- 2 cells were subjected to normoxia $\left(\mathrm{N}, 21 \% \mathrm{O}_{2}\right)$ or hypoxia $\left(\mathrm{H}, 0.2 \% \mathrm{O}_{2}\right)$ for $24 \mathrm{~h}$. Transcript quantification for TGF $\beta$ (a), ACTA2 (b), vimentin (c), CDH1 (d), CDH2 (e), COL1A1 (f), COL3A1 (g), COL4A1 (h), MMP2 (i), MMP9 (j), MMP3 (k) and

TIMP1 (I). Statistical analysis was performed using Student's $t$ test. Results are representative of mean + SEM of 2 independent experiments performed with 6 replicates; ${ }^{*} p<0.05$; ${ }^{* *} p<0.01$; $* * * p<0.001 ; * * * * p<0.0001$.

signals might contribute to the induction of EMT and cancer progression in these studies. In a study using hypoxic pulmonary endothelial cells, Liu et al. [26] showed a transient inhibition of vimentin expression, as well as a redistribution of vimentin filament networks, that could influence endothelial barrier stabilization. Overall, it is apparent that context and concurrent signals modulate adaptive fibrotic responses to hypoxia in the intestinal mucosa. This is further supported by the fact that none of the mesenchymal markers tested (i.e., ACTA2, vimentin, and $\mathrm{CDH} 2$ ) were affected by hypoxia in mice. Intriguingly, hypoxia failed to reduce basal levels of TGF $\beta$ mRNA expression in fibroblasts, IECs, and macrophages. Our results suggest that hypoxia anti-fibrotic effects involve the selective reduction of the expression of TGF $\beta$ downstream target factors, but not TGF $\beta$, whose immunomodulatory properties are crucial for the maintenance of mucosal homeostasis. It should also be noted that members of the TGF $\beta$ family have been proposed to have redun-

dant roles in the modulation of biological processes [27]. Interestingly, the potent anti-scarring cytokine TGF $\beta 3$ has been shown to be induced by HIF-1a in mouse embryonic fibroblasts [28].

In our hands, colonic biopsies of human subjects showed a tendency towards a reduction in the mRNA levels of the collagen chains COL1A1 and COL4A1 under hypoxia. In addition, mice subjected to hypoxia presented significantly reduced levels of colonic COL1A1, COL3A1, and COL4A1, confirming a reduction in the production of ECM proteins in vivo under low oxygen conditions. Importantly, and in line with these results, hypoxia significantly reduced basal expression of COL1A1, COL3A1, and COL4A1 in human fibroblasts, the main cells responsible for collagen production. The impact of hypoxia on the production of different collagen types is controversial, and promoting and inhibitory effects have been reported. Thus, hypoxia induces the expression of collagen I in dermal and pulmonary fibro- 


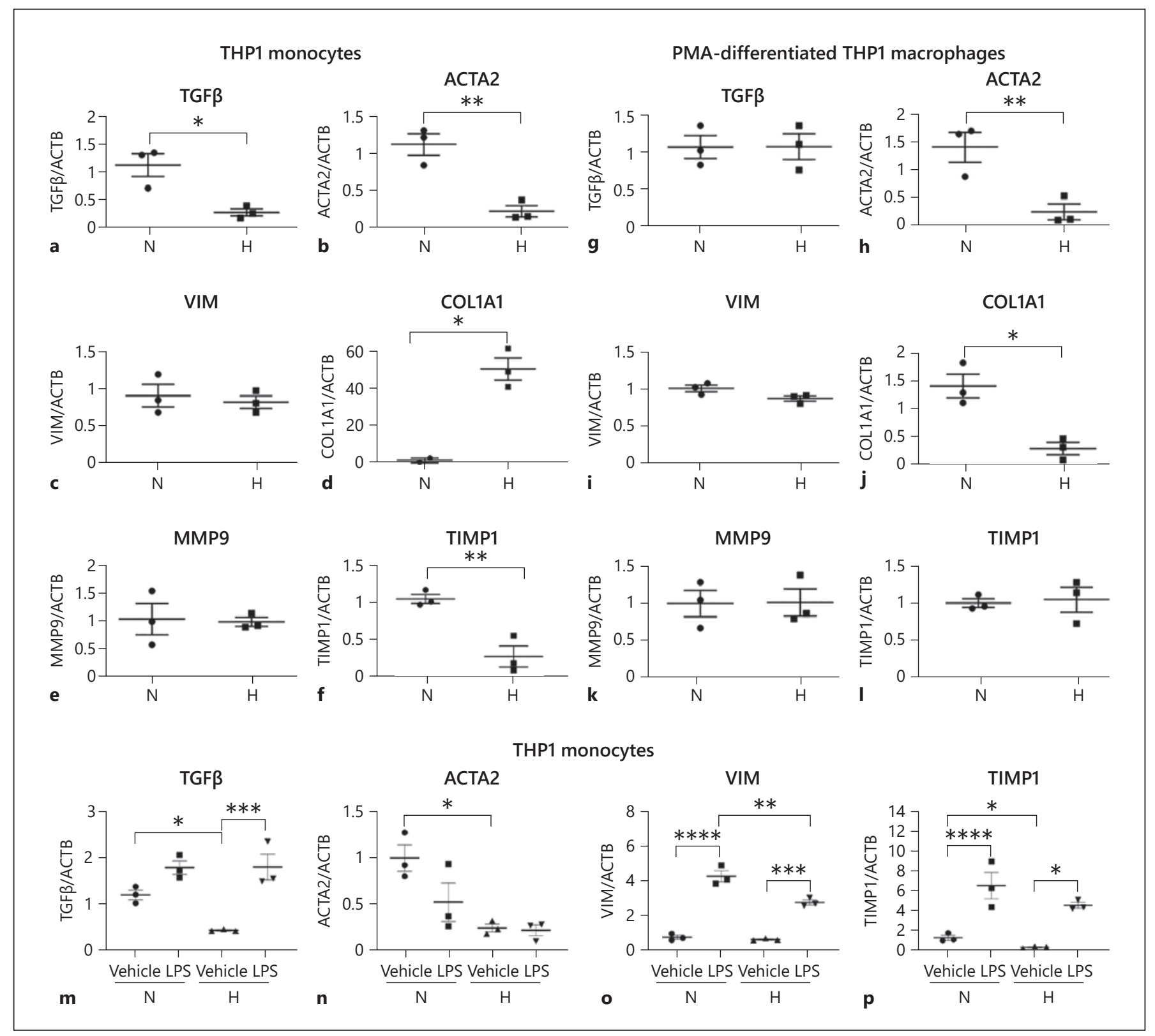

Fig. 6. Hypoxia reduces the expression of fibrotic markers in monocytes. THP-1 monocytes and PMA-differentiated THP-1 macrophages were subjected to normoxia $\left(\mathrm{N}, 21 \% \mathrm{O}_{2}\right)$ or hypoxia $\left(\mathrm{H}, 0.2 \% \mathrm{O}_{2}\right)$ for $24 \mathrm{~h}$. Transcript quantification for TGF $\beta(\mathbf{a}, \mathbf{g})$, $\operatorname{ACTA2}(\mathbf{b}, \mathbf{h})$, vimentin $(\mathbf{c}, \mathbf{i}), \operatorname{COL} 1 \mathrm{~A} 1(\mathbf{d}, \mathbf{j}), \operatorname{MMP} 9(\mathbf{e}, \mathbf{k})$, and TIMP1 (f, I) was performed. THP-1 monocytes were subjected to normoxia or hypoxia for $24 \mathrm{~h}$ in the absence or presence of $10 \mu \mathrm{g} /$

blasts [29], as well as hydroxylases essential for collagen 1 fibre formation [30]. Conversely, the expression of COL2A 1 and COL5A2 is reduced after 7 days of hypoxia in chondrocites [31]. Duval et al. [32] showed that HIF-1a overexpression reduced the expression levels of COL1A1,
mL LPS, and transcript quantification for TGF $\beta(\mathbf{m}), \operatorname{ACTA2}(\mathbf{n})$, vimentin (o), and TIMP1 (p) was performed. Statistical analysis was performed using Student's $t$ test. Results are representative of mean + SEM of 2 independent experiments performed at least with 3 triplicates; ${ }^{*}, p<0.05$; $^{* *}, p<0.01$; $^{* * *}, p<0.001$; $^{* * *}, p<0.0001$. PMA, phorbol 12-myristate-13-acetate.

COL1A2, and COL3A, thereby preventing the redifferentiation of human chondrocytes. These authors concluded that hypoxia inhibits fibroblast-like phenotype markers. In a study using human peritoneal mesothelial cells, $6 \mathrm{~h}$ of hypoxia increased the expression of collagen III, while 
collagen I was mildly decreased [33]. These controversial findings could be ascribed to the cell type used and the time point studied, as lower exposition times to hypoxia seem to reduce collagen expression over longer times. In a study assessing collagen I fibre density in invasive solid breast and prostate tumour models, Kakkad et al. [34] detected fewer and structurally altered collagen I fibres in hypoxic tumour areas when compared with normoxic tumour regions. These authors attributed the more porous collagen I fibre matrix present in hypoxic regions to the proteolytic degradation of collagen I and reduced collagen I production. Interestingly, hypoxia selectively reduced the expression of network-forming COL4A1, but not collagens COL1A1 and COL3A1 in Caco- 2 cells. It is noteworthy that collagen IV, the main constituent of the basal lamina, has been shown to contribute to Caco-2 spreading and migration [35].

Hypoxia reduced the mRNA expression of the metalloproteinase inhibitor TIMP1 in the colon of healthy individuals. Moreover, TIMP1 also showed a trend towards reduced protein levels in healthy subjects as well as IBD patients 1 week after hypoxia. Accordingly, hypoxia reduced the expression of TIMP1 in the colon of healthy and DSStreated mice. Unlike other fibrotic and tissue remodelling factors, TIMP1 was consistently downregulated in primary gut fibroblasts, IECs, and monocytes, suggesting that TIMP1 is a primary target of hypoxia [36]. In this regard, hypoxia has been shown to decrease TIMP1 mRNA and protein expression in synovial fibroblasts from patients with rheumatoid arthritis [37]. In rats, maternal hypoxia decreased TIMP1 and TIMP2 expression in neuronal cells in the pups [38]. Previous reports have evidenced the accumulation of HIF-1 in mice administered with the hydroxylase inhibitor and the HIF-1 inducer DMOG [12, 21]. Interestingly, and most important to understand the mechanism underlying the expression of TIMP1 under hypoxia, DSS-treated mice administered with DMOG showed a decrease in the colonic mRNA expression of TIMP1, as well as MMP9, MMP3, and MMP13, pointing to the important role of HIF in the regulation of these genes under hypoxic conditions. Hypoxia significantly reduced the expression of MMP3 and MMP9, but not MMP2 in the colon of healthy mice, indicating selective effects on the expression of ECMdegrading enzymes. A similar expression profile was observed in cultured IECs and primary gut fibroblasts, but not macrophages, suggesting that IECs and fibroblasts are the main contributors to the effects observed in vivo. Apart from its ability to degrade ECM proteins, MMP3 can also activate other MMPs such as MMP1, MMP7, MMP9, and MMP13 [39, 40]. Therefore, reduction of MMP3 expres- sion under hypoxia would further hinder MMP9-associated enzymatic activities. The differential effects on the expression of the 2 gelatinases MMP2 and MMP9 might reflect the opposing roles of these MMPs on maintenance of intestinal barrier function, with MMP9 being destructive and MMP2 protective [41]. It is also worth noting that MMP3 and MMP9 are mainly regulated at transcriptional and translational levels, whereas MMP2 activity is primarily controlled by proteolytic cleavage of the proenzyme by TIMPs [42], which suggest that alternative mechanisms could be in place to regulate MMP2 activity. The substrates of MMP3 and MMP9 also include cytokines, such as IL-1 $\beta$ [43] and TGF $\beta$ [44]. As a consequence, hypoxia-associated reduction in MMP3 and MMP9 expression may play a role in the downregulation of inflammatory responses observed in previous studies.

The effects of hypoxia on IBD are controversial, with studies showing detrimental and protective effects. Thus, recent studies indicate that high-altitude journeys and flights-associated hypoxia heighten the risk of flares in IBD patients $[45,46]$, and high-altitude hikes increase the expression of inflammatory cytokines in the small intestine in healthy subjects [47]. On the other hand, there is mounting evidence that hypoxia ameliorates inflammation in several models of IBD and IBD patients [11, 12, $48,49]$, mainly through the enhancement of intestinal barrier function [50]. In transgenic mice, lack of HIF-1a expression in the epithelium led to a more severe colitis, while constitutively active HIF- 1 was protective $[6,51$, 52]. Our data on the impact of hypoxia on the expression of fibrotic factors under inflammatory conditions are limited, and we could only show the effect on tissue remodelling markers, that is, TIMP1 and several MMPs. Moreover, post-transcriptional and post-translational modifications play a crucial role in the activity of a number of factors involved in fibrosis, such as TGF $\beta$, MMPs, and collagens, and assessing the protein expression and activity of these factors is crucial to clarify the functional impact of hypoxia on fibrosis. Further research is needed to elucidate to what extent the observed effects influence the development of IBD-associated intestinal fibrosis.

In summary, our results suggest that hypoxia preserves the epithelial phenotype of IECs by reducing the expression of pro-fibrotic markers and blocks constitutive expression of factors involved in tissue remodelling, ECM deposition, tissue degradation, and cell migration in the intestinal mucosa. Hypoxia may not only modulate inflammatory processes in the gut but also reduce inflammation-associated fibrosis through the transcriptional regulation of fibrosis-associated factors.
Simmen et al. 


\section{Acknowledgements}

We thank Mirjam Blattmann, Nicole obialo, and Sylvie Scharl for organizing and collecting the human colon biopsies. Mehdi Madanchi is gratefully acknowledged for his help in collecting the human subject data. We extend our special appreciation to the $\mathrm{Zu}$ rich Integrative Rodent Physiology (ZIRP) core facility of the University of Zurich for their support in the animal experiments.

\section{Statement of Ethics}

This research was conducted ethically in accordance with the World Medical Association Declaration of Helsinki. Subjects have given their written informed consent, and the study protocol was approved by the institute's committee on human research.

\section{Conflict of Interest Statement}

The authors declare that there is no conflict of interest.

\section{Funding Sources}

The authors received no financial support for the research, authorship, and/or publication of this article.

\section{Author Contributions}

S.S.: data acquisition and manuscript preparation; M.M., S.R., K.B., S.L., J.C.R., K.A., P.S., and B.W.: data acquisition; I.F.W., R.H.W., J.Z., S.R.V., G.R., C.d.V., and M.H.: critical revision of the manuscript for important intellectual content; and P.A.R.: study supervision, data acquisition, and manuscript preparation.

\section{References}

1 Suzuki K, Sun X, Nagata M, Kawase T, Yamaguchi H, Sukumaran V, et al. Analysis of intestinal fibrosis in chronic colitis in mice induced by dextran sulfate sodium. Pathol Int. 2011 Apr;61(4):228-38.

2 Burke JP, Mulsow JJ, O'Keane C, Docherty NG, Watson RW, O'Connell PR. Fibrogenesis in Crohn's disease. Am J Gastroenterol. 2007 Feb;102(2):439-48.

3 Rieder F, Zimmermann EM, Remzi FH, Sandborn WJ. Crohn's disease complicated by strictures: a systematic review. Gut. 2013 Jul;62(7):1072-84.

4 Ruthenborg RJ, Ban JJ, Wazir A, Takeda N, Kim JW. Regulation of wound healing and fibrosis by hypoxia and hypoxia-inducible factor-1. Mol Cells. 2014 Sep 30;37(9):637-43.

5 Giatromanolaki A, Koukourakis MI, Koutsopoulos AV, Harris AL, Gatter KC, Sivridis E. Autophagy and hypoxia in colonic adenomas related to aggressive features. Colorectal Dis. 2013 May; 15(5):e223-30.

6 Karhausen J, Furuta GT, Tomaszewski JE, Johnson RS, Colgan SP, Haase VH. Epithelial hypoxia-inducible factor- 1 is protective in murine experimental colitis. J Clin Invest. 2004 Oct;114(8):1098-106.

7 Taylor CT, Colgan SP. Hypoxia and gastrointestinal disease. J Mol Med. 2007 Dec;85(12): 1295-300.

8 Scholz CC, Taylor CT. Targeting the HIF pathway in inflammation and immunity. Curr Opin Pharmacol. 2013 Aug;13(4):64653.

9 Wang GL, Jiang BH, Rue EA, Semenza GL. Hypoxia-inducible factor 1 is a basic-helixloop-helix-PAS heterodimer regulated by cellular O2 tension. Proc Natl Acad Sci U S A. 1995 Jun 6;92(12):5510-4

10 Ivan M, Kondo K, Yang HF, Kim W, Valiando J, Ohh M, et al. HIF alpha targeted for VHL- mediated destruction by proline hydroxylation: Implications for O-2 sensing. Science. 2001 Apr 20;292(5516):464-8.

11 Furuta GT, Turner JR, Taylor CT, Hershberg RM, Comerford K, Narravula S, et al. Hypoxia-inducible factor 1-dependent induction of intestinal trefoil factor protects barrier function during hypoxia. J Exp Med. 2001 May 7; 193(9):1027-34.

12 Cosin-Roger J, Simmen S, Melhem H, Atrott K, Frey-Wagner I, Hausmann M, et al. Hypoxia ameliorates intestinal inflammation through NLRP3/mTOR downregulation and autophagy activation. Nat Commun. $2017 \mathrm{Jul}$ 24;8(1):98.

13 Manresa MC, Godson C, Taylor CT. Hypoxia-sensitive pathways in inflammation-driven fibrosis. Am J Physiol Regul Integr Comp Physiol. 2014 Dec 15;307(12):R1369-80.

14 Ignotz RA, Massagué J. Transforming growth factor-beta stimulates the expression of fibronectin and collagen and their incorporation into the extracellular matrix. J Biol Chem. 1986 Mar 25;261(9):4337-45.

15 Kalluri R, Weinberg RA. The basics of epithelial-mesenchymal transition. J Clin Invest. 2009 Jun;119(6):1420-8.

16 Simmen S, Cosin-Roger J, Melhem H, Maliachovas $\mathrm{N}$, Maane M, Baebler K, et al. Iron prevents hypoxia-associated inflammation through the regulation of nuclear factor- $\mathrm{\kappa B}$ in the intestinal epithelium. Cell Mol Gastroenterol Hepatol. 2019;7(2):339-55.

17 de Vallière C, Cosin-Roger J, Simmen S, Atrott K, Melhem H, Zeitz J, et al. Hypoxia positively regulates the expression of $\mathrm{pH}$ sensing G-protein coupled receptor OGR1 (GPR68). Cell Mol Gastroenterol Hepatol. 2016;2:796-810.

18 Vavricka S, Ruiz PA, Scharl S, Biedermann L, Scharl M, de Vallière C, et al. Protocol for a prospective, controlled, observational study to evaluate the influence of hypoxia on healthy volunteers and patients with inflammatory bowel disease: the Altitude IBD Study. BMJ Open. 2017 Jan 05;7(1):e013477.

19 Schneider CA, Rasband WS, Eliceiri KW. NIH Image to ImageJ: 25 years of image analysis. Nat Methods. 2012 Jul;9(7):671-5.

20 Obermeier F, Kojouharoff G, Hans W, Schölmerich J, Gross V, Falk W. Interferongamma (IFN-gamma)- and tumour necrosis factor (TNF)-induced nitric oxide as toxic effector molecule in chronic dextran sulphate sodium (DSS)-induced colitis in mice. Clin Exp Immunol. 1999 May;116(2):238-45.

21 Cummins EP, Seeballuck F, Keely SJ, Mangan NE, Callanan JJ, Fallon PG, et al. The hydroxylase inhibitor dimethyloxalylglycine is protective in a murine model of colitis. Gastroenterology. 2008 Jan;134(1):156-65.

22 Leeb SN, Vogl D, Falk W, Schölmerich J, Rogler G, Gelbmann CM. Regulation of migration of human colonic myofibroblasts. Growth Factors. 2002 Jun;20(2):81-91.

$23 \mathrm{Wu}$ CC, Bratton SB. Regulation of the intrinsic apoptosis pathway by reactive oxygen species. Antioxid Redox Signal. 2013 Aug 20; 19(6):546-58.

24 Bressenot A, Marchal S, Bezdetnaya L, Garrier J, Guillemin F, Plénat F. Assessment of apoptosis by immunohistochemistry to active caspase-3, active caspase-7, or cleaved PARP in monolayer cells and spheroid and subcutaneous xenografts of human carcinoma. J Histochem Cytochem. 2009 Apr;57(4): 289-300.

25 Daly CS, Flemban A, Shafei M, Conway ME, Qualtrough D, Dean SJ. Hypoxia modulates the stem cell population and induces EMT in the MCF-10A breast epithelial cell line. Oncol Rep. 2018 Feb;39(2):483-90.
Hypoxia Reduces Fibrotic Gene

Expression in the Gut
Inflamm Intest Dis 2021;6:87-100 DOI: $10.1159 / 000513061$ 
26 Liu T, Guevara OE, Warburton RR, Hill NS, Gaestel M, Kayyali US. Regulation of vimentin intermediate filaments in endothelial cells by hypoxia. Am J Physiol Cell Physiol. 2010 Aug;299(2):C363-73.

27 Morikawa M, Derynck R, Miyazono K. TGFbeta and the TGF-beta family: context-dependent roles in cell and tissue physiology. Cold Spring Harb Perspect Biol. 2016 May 2;8(5): a021873.

28 Scheid A, Wenger RH, Schäffer L, Camenisch I, Distler O, Ferenc A, et al. Physiologically low oxygen concentrations in fetal skin regulate hypoxia-inducible factor 1 and transforming growth factor-beta3. FASEB J. 2002 Mar;16(3):411-3.

29 Mingyuan X, Qianqian P, Shengquan X, Chenyi Y, Rui L, Yichen S, et al. Hypoxia-inducible factor- $1 \alpha$ activates transforming growth factor- $\beta 1 /$ Smad signaling and increases collagen deposition in dermal fibroblasts. Oncotarget. 2018 Jan 9;9(3):3188-97.

30 Hofbauer KH, Gess B, Lohaus C, Meyer HE, Katschinski D, Kurtz A. Oxygen tension regulates the expression of a group of procollagen hydroxylases. Eur J Biochem. 2003 Nov; 270(22):4515-22.

31 Grimshaw MJ, Mason RM. Modulation of bovine articular chondrocyte gene expression in vitro by oxygen tension. Osteoarthr Cartil. 2001 May;9(4):357-64.

32 Duval E, Leclercq S, Elissalde JM, Demoor M, Galéra P, Boumédiene K. Hypoxia-inducible factor lalpha inhibits the fibroblast-like markers type I and type III collagen during hypoxia-induced chondrocyte redifferentiation: hypoxia not only induces type II collagen and aggrecan, but it also inhibits type I and type III collagen in the hypoxia-inducible factor 1alpha-dependent redifferentiation of chondrocytes. Arthritis Rheum. 2009 Oct; 60(10):3038-48.

33 Saed GM, Zhang W, Chegini N, Holmdahl L, Diamond MP. Alteration of type I and III collagen expression in human peritoneal mesothelial cells in response to hypoxia and transforming growth factor-beta1. Wound Repair Regen. 1999 Nov-Dec;7(6):504-10.

34 Kakkad SM, Solaiyappan M, O’Rourke B, Stasinopoulos I, Ackerstaff E, Raman V, et al. Hypoxic tumor microenvironments reduce collagen I fiber density. Neoplasia. 2010 Aug; 12(8):608-17.

35 Sanders MA, Basson MD. Collagen IV regulates Caco-2 cell spreading and p130Cas phosphorylation by FAK-dependent and FAK-independent pathways. Biol Chem. 2008 Jan;389(1):47-55.

36 Wang J, Ni Z, Duan Z, Wang G, Li F. Altered expression of hypoxia-inducible factor-1alpha (HIF-1alpha) and its regulatory genes in gastric cancer tissues. PLoS One. 2014;9(6): e99835.

37 Cha HS, Ahn KS, Jeon CH, Kim J, Song YW, Koh EM. Influence of hypoxia on the expression of matrix metalloproteinase-1, -3 and tissue inhibitor of metalloproteinase- 1 in rheumatoid synovial fibroblasts. Clin Exp Rheumatol. 2003 Sep-Oct;21(5):593-8.

38 Tong W, Chen W, Ostrowski RP, Ma Q, Souvenir R, Zhang L, et al. Maternal hypoxia increases the activity of MMPs and decreases the expression of TIMPs in the brain of neonatal rats. Dev Neurobiol. 2010 Feb 15;70(3): 182-94.

39 Ye S, Eriksson P, Hamsten A, Kurkinen M, Humphries SE, Henney AM. Progression of coronary atherosclerosis is associated with a common genetic variant of the human stromelysin-1 promoter which results in reduced gene expression. J Biol Chem. 1996 May 31;271(22):13055-60.

40 Yamamoto K, Okano H, Miyagawa W, Visse $\mathrm{R}$, Shitomi Y, Santamaria S, et al. MMP-13 is constitutively produced in human chondrocytes and co-endocytosed with ADAMTS-5 and TIMP- 3 by the endocytic receptor LRP1. Matrix Biol. 2016 Dec;56:57-73.

41 Garg P, Rojas M, Ravi A, Bockbrader K, Epstein S, Vijay-Kumar M, et al. Selective ablation of matrix metalloproteinase-2 exacerbates experimental colitis: contrasting role of gelatinases in the pathogenesis of colitis. J Immunol. 2006 Sep 15;177(6):4103-12.

42 Fahling M, Perlewitz A, Doller A, Thiele BJ. Regulation of collagen prolyl 4-hydroxylase and matrix metalloproteinases in fibrosarcoma cells by hypoxia. Comp Biochem Physiol C Toxicol Pharmacol. 2004 Oct;139(1-3):119-26.

43 Schonbeck U, Mach F, Libby P. Generation of biologically active IL- 1 beta by matrix metalloproteinases: a novel caspase-1-independent pathway of IL-1 beta processing. J Immunol. 1998 Oct 1;161(7):3340-6.

$44 \mathrm{Yu}$ Q, Stamenkovic I. Cell surface-localized matrix metalloproteinase- 9 proteolytically activates TGF-beta and promotes tumor invasion and angiogenesis. Genes Dev. 2000 Jan 15;14(2):163-76.

45 Vavricka SR, Rogler G, Maetzler S, Misselwitz B, Safroneeva E, Frei P, et al. High altitude journeys and flights are associated with an increased risk of flares in inflammatory bowel disease patients. J Crohns Colitis. 2014 Mar; 8(3):191-9.

46 Vavricka SR, Rogler G, Biedermann L. High altitude journeys, flights and hypoxia: any role for disease flares in IBD patients? Dig Dis. 2016;34(1-2):78-83.

47 Wojtal KA, Cee A, Lang S, Götze O, Frühauf $\mathrm{H}$, Geier A, et al. Downregulation of duodenal SLC transporters and activation of proinflammatory signaling constitute the early response to high altitude in humans. Am J Physiol Gastrointest Liver Physiol. 2014 Oct 1;307(7): G673-88.

48 Mariani F, Sena P, Marzona L, Riccio M, Fano $\mathrm{R}$, Manni $\mathrm{P}$, et al. Cyclooxygenase- 2 and $\mathrm{Hy}$ poxia-Inducible Factor-1alpha protein expression is related to inflammation, and upregulated since the early steps of colorectal carcinogenesis. Cancer Lett. 2009 Jul 8;279(2): 221-9.

49 Matthijsen RA, Derikx JP, Kuipers D, van Dam RM, Dejong CH, Buurman WA. Enterocyte shedding and epithelial lining repair following ischemia of the human small intestine attenuate inflammation. PLoS One. 2009 Sep 15;4(9):e7045.

50 Manresa MC, Taylor CT. Hypoxia inducible factor (HIF) hydroxylases as regulators of intestinal epithelial barrier function. Cell Mol Gastroenterol Hepatol. 2017 May;3(3):303-15.

51 Keely S, Campbell EL, Baird AW, Hansbro PM, Shalwitz RA, Kotsakis A, et al. Contribution of epithelial innate immunity to systemic protection afforded by prolyl hydroxylase inhibition in murine colitis. Mucosal Immunol. 2014 Jan;7(1):114-23.

52 Xue X, Ramakrishnan SK, Shah YM. Activation of HIF-1 $\alpha$ does not increase intestinal tumorigenesis. Am J Physiol Gastrointest Liver Physiol. 2014 Jul 15;307(2):G187-95. 